NBER WORKING PAPER SERIES

$$
w_{10}^{P} 3
$$

ROSEPACK Document No. I

Semi-portability of FORTRAN Programs

Neil E. Kaden*

Virginia Klema*

\begin{abstract}
Working Paper No. 103
Computer Research Center for Economics and Management Science National Bureau of Economic Research, Inc.

575 Technology Square Cambridge, Massachusetts 02139
\end{abstract}

September 1975

Preliminary: not for quotation

NBER working papers are distributed informally and in limited numbers for conments only. They should not be quoted without written permission.

This report has not undergone the review accorded official NBER publications; in particular, it has not yet been submitted for approval by the Board of Directors.

* NBER Computer Research Center. Research supported in part by National Science Foundation Grant \#DCR 75-08802 to the National Bureau of Economic Research, Inc. 
Table of Contents

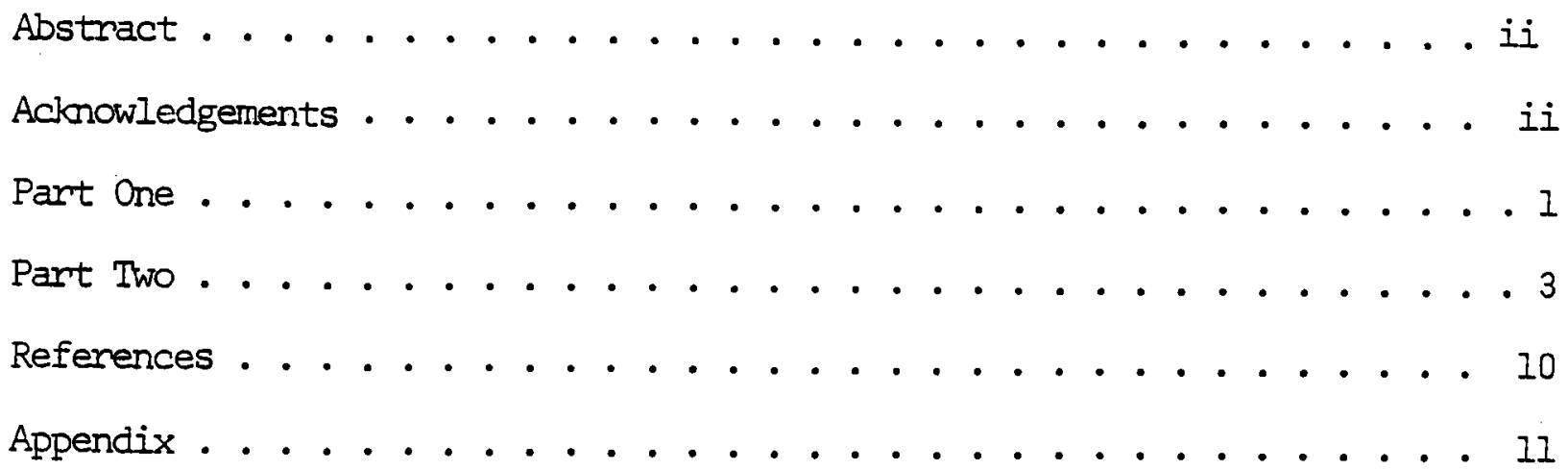




\begin{abstract}
Transferring Fortran subroutines from one manufacturer's machine to another or from one operating system to another puts certain constrains on the construction of the Fortran statements that are used in the subroutines. The reliable performance of this mathematical software should be unaffected by the host environment in which the software is used or by the compiler from which the code is generated. In short, the algorithm is to be independent of the computing environment in which it is run.

The subroutines of ROSEPACK (Robust Statistics Estimation Package) are Fortran IV source code designed to be semi-portable where semi-portable is defined to mean transportable with minimum change.*
\end{abstract}

\title{
Acknowledgments
}

The authors wish to thank J. Boyle and W. Cody for sharing their internal document on programming conventions, J. Kirsch for his helpful suggestions on documentation of subroutines, D. Hoaglin and G. Ruderman for their constructive criticism of this document, and Sheila Howard for her careful typing of the manuscript.

"Cody, W.J., "The Construction of Numerical Subroutine Libraries," SIAM Review, Vol. 16, No. 1, pp. 36-46, January (1974). 
Seni-portability of Fortran subroutines puts certain constraints on the construction of Fortran statements, the declaration of variables, and the representation of constants that are used in the subroutines. Many of these constraints are needed for Fortran subroutines that are to be imbedded in applications subsysters that are written in another language, say PL/I.

Inevitably, the numerical algebra algorithms themselves are strengthened when their performance is unaffected by the arithmetic of the machine on which they are used and the Fortran compiler by which their code is generated.

The rules fon structured programing $[1,2,3]$, and structured documentation (see Part Two, Section $X$ of this document) should be followed insofar as possible. The comments within the program or subroutine should be sufficient to inform the user about input parameters, output parameters, temporary storage parameters, error exits, and the algorithm that the program inplements.

This document presents certain suggestions for programring that will tend toward requirements for semi-portability of ANSI Fortran IV (as described in CACM, Vol. 7, No. 10, October '64) subroutines and programs. We also suggest certain conventions for comments and general formatting of the Fortran code. By "formatting" we mean the spacing and indentation that detemine the general appearance and readability of the code. Such formatting is suggested to help the reader or the user understand the algorithn, the program, and the flow of control within the program.

\section{Part One}

The suggestions for programing are

I. COMMON storage should not be used for arrays. This is not an ANSI restriction, but driver programs become simplen to write, and the use in a paged environment is erhanced if one does not use COMMON.

II. All array arguments should have adjustable dimensions. These dimensions should be made explicit in the declarations of the formal parameters for each subroutine. For example, 
REAL $\quad A(N M, N)$

not

REAL $A(N M, 1)$

III. EQUIVAIENCE statements should not be used.

IV. Certain Fortran compilers do not distinguish more than six characters of an identifier. Hold identifiers to six characters or fewer.

V. Do not use miltiple entry points or non-standard retums.

VI. Be sure that the precision of any Fortran library routine or built-in function is explicit in all statements. For example, DABS, not ABS, for absolute value for long precision computing. Do not use mixed mode arithmetic or assume there is an implied conversion anywhere, not even for constants. For example

DØUBLE PRECISION X

$\mathrm{X}=\mathrm{X}+10.0 \mathrm{D} 0$

not

DØUBLE PRECISION X

$x=x+10.0$

VII. Constants that are used in iterations or convergence criteria should be functions of the machine's precision, i.e., the smallest floating point number, $\varepsilon$, representable in the machine for which the floating representation of $I+\varepsilon>1$. Certainly, a constant that cannot be converted precisely on the machine should never be used. For example, .1, is representative of such numbers.

VIII. Test cases must be devised so that data can be converted uniformly on all target machine. The word length of the machine determines the truncation of the intemal representation of floating point numbers, and conversion routines do not treat floating point numbers uniformly. The integers are treated uniformly with respect to conversion so long as they lie within the precision range of arithmetic of the computing machine. One suggestion for portability for test cases used as input numbers is to read them in as integers and then DFLOAT to get the floating point representations.

IX. Obscune underflows can often produce side effects that give divide checks or overflows. This problem is particularly acute because the range of arithmetic on many machines is not symmetric about zero. For example, the range of arithmetic on the IBM $360 /$ 370 machines is about $10^{35}>|x|>10^{-78}$. That an algorithm will exhibit overflow, underflow, or divide check problems is often not known in advance. However, some linear systems routines have this problem when an inner product is formed or when multiple divides are encountered. Be prepared to isolate such problems. 
One solution is to reorder arithmetic expression. Another solution is to resort to extended precision arithmetic for those critical sections of code.

X. The usual rules for separate sections for error handling and input-output that are required for applications subsystems are equally applicable for semi-portable Fortran programs. The error handling from the subroutines should be uniform. The input-output should be confined to main programs or special I- $\emptyset$ subroutines; that is to say, computation subroutines should be I- $\emptyset$ free. The goal of the error recovery is to permit computation to continue without resorting to system termination.

$X I$. We expect the subroutines in ROSEPACK to be compiled with Fortran compilers with the highest level of optimization. We have not used hand optimization in the subroutines

Part Two

The suggestions for formatting are

I. Identifiers

Identifiers, i.e., variable names, should correspond to default declarations in Fortran. However, explicit declarations should be written for each identifier.

Variables from the calling sequence, internal variables, and function names should all be declared separately. For a suggestion on how to accomplish this see X Internal Documentation Section B (PARAMEIERS), Section C (LOCAL VARIABLES), and Section D (FUNCTIONS) of the description of the Prologue.

II. Labels

If the order of labels within a subroutine is not linear the convention used should be explicitly described. This ordering of statement labels should be linear and could proceed in multiples of 10 for interion program sections. The next level of program section could proceed as 100 , and perhaps the next as 1000 .

Do not use unreferenced labels.

Code for error exits should be surrounded by conments and located at the end of the program or subroutine. The labels for error exits should be 2 or 3 digits, the first of which is 9 , the last non-zero.

One format statement may be used by more than one print statement in a program. Therefore we suggest that all format statements be labeled with 4 digit numbers the last of which is nonzero and placed after RETURN and before END of the program. 
Preferably all input-output should be written in subroutine form. We suggest that a DATA statement be used to fix units of I- $\varnothing$ and that this DATA statement be made particular to a given installation.

The variables containing this I- $\varnothing$ unit information should be passed as parameters to all subroutines using these I- $\emptyset$ units. This device allows a global change of an $I-\emptyset$ unit without recompiling individual subroutines.

III. Use of blank spaces

There should not be extra blank spaces around dumy variables or constants in DO loops. Blank spaces should delimit = symbols in assignment statements. Blank spaces should be used wherever such use will enhance readability of elements of expressions or statements.

IV. Tab Spacings

Throughout this document we are assuming tab setting in colums $1,7,10,15,20,25$, etc.

V. Continuation Characters

Second and subsequent lines of all continuation statements should be numbered 1 through 9 , then $A$ through $Z$ in colum 6 . The text of each continuation statement should be indented one tab space from the initial line of the statement.

VI. $\quad$ DØ loops

$A l l$ D $\emptyset$ loops should be surmounded by comment statements which may be blank. Text conments should follow a blank comment statement. If more than one statement is in the range of a DO loop, the closing statement of the DO loop should be a CONIINUE. This CONTINUE should be unambiguous. Statements between DO and CONTINUE should be indented one additional tab space to correspond to a block structure.

Inner loops should be indented one tab space to the right of their surrounding outer loop.

For examples of indentation of DO loops see the examples in Appendix $I$.

VII. DATA Statements

Data statements should be used to set installation-dependent constants, such as data-set numbers for I/O, and machine precisions, underflow tolerances, or other machine-dependent constants. See X, Internal Documetnation, Section L, for more details.

If a non-numeric character string must be used in a DATA statement, it should be packed as one character per machine word and always stored in an array. 
VIII. Structured programing

The programing and formatting conventions that we describe are similar to structured programming in the following ways:

1. format for readability and understanding

2. indentation for major and minor loops

3. array dimensions are adjustable

4. temporary storage arrays are passed as parameters

5. documentation is structured such that it is contained within the routine.

IX. Printed output

All printed output should be formatted such that it is not greater than 8 1/2 inches in width. Most line printers print 10 characters per inch, and 80 characters per line allows ample margins. This will greatly aid in reproduction of the output.

X. Intemal Documentation

All Fortran programs should be well documented by liberal use of comment statements. Proper documentation will enhance readability and appearance of the code, improve understanding of the algorithm used, help ensure proper use of the program, and aid in future modifications. When semi-portability is also considered, proper documentation serves to isolate those portions of the code which are installation-dependent.

In-line documentation of Fortran programs can be considered in two major sections, the Prologue and the Program-flow comments. The latter consists of the comment statements embedeled within the code describing how the algorithm is being carried out as the flow of control passes from statement to statement. The former consists of certain non-executable FORTRAN statements found at the beginning of the subprogram which fully describe the proper use of the software, as well as information concerning its development. Any user familiar with the guidelines has the added advantage of knowing where to find specific information concerming the program. The Prologue also identifies and isolates installation-dependent aspects of the program and thus enhances semi-portability. The Prologue is the major documentation for the use of the program subroutine.

Program-flow comments should be delimited by special characters to enhance their readability and appearance. In ROSEPACK the colon (:) is used. Such comments should also follow the rules for statement indentation described elsewhere in this document.

In most cases, the text of the comment should be preceded and followed by a string of 10 special characters (colons). At least 
one blank space, but not more than three blank spaces, should be put between the special character strings and the text of the comment. If this method is used for a comment extending over several lines, all lines should have a " $C$ " in column 1 , and all but the first line should be indented one additional tab (beyond the current level of indentation).

Building on the suggestions of Boyle and Cody, an alternative method of delimiting comments, reconmended for important comments or those extending over several lines, is to surround them by a "box" of special characters. The following is an example of what is meant by a "box":

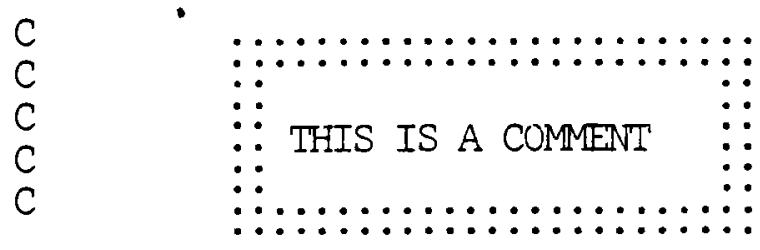

Blank comment statements (i.e., conment statements containing blanks in columns 2 through 72) may be used wherever their use enhances the readability of the program.

The statement inmediately before the END statement should always be a comment statement delimiting the end of the program and containing the name of the program. An example follows:

\section{C $\quad$ : $::::::::$ LAST CARD OF (NAME OF SUBROUTINE) $:::::::::$ : \\ END}

The Prologue consists of the declarations of the calling sequence and variable names of the subprogram, a number of sections of text on the subprogram, and any DATA or EQUIVAIENCE statements. It contains a number of headings denoting the different logical sections of the Prologue. The headings are comment statements with the character "*" in columns 7 through 11 and the heading name beginning in column 12 and followed by a colon (:). A blank comment statement should not immediately follow a heading. If the section denoted by the heading line is empty, the heading should be followed by a comment statement containing "NONE" in colums 7 through 10 and then a blank comment statement.

The different headings, in the order they should appear, are:

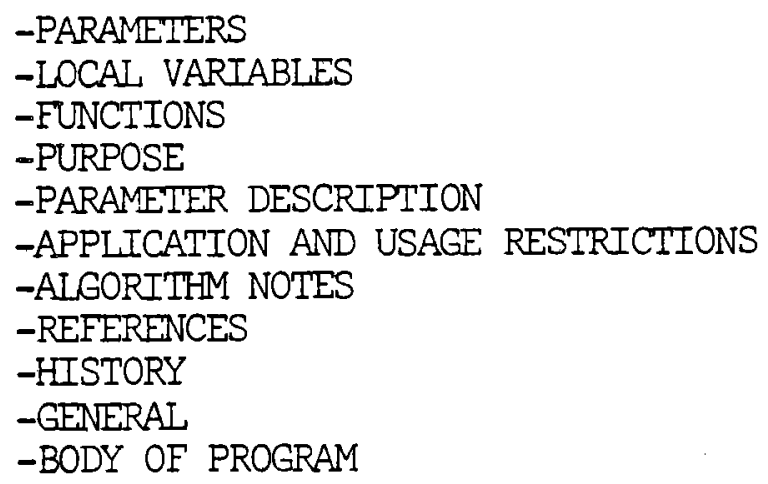


Three delimiter lines, consisting of a blank comment statement, a comment statement consisting of the special character colon (:) in columns 7 through 72, and then a second blank conment statement, should occur immeidately before the purpose heading and immediately after the GENERAL section. All lines between these delimiters should be comment statements. When columns 73 through 80 of each card contain serialization or identification characters, this gives a box-like appearance to the part of the Prologue containing text.

An example of two programs following these guidelines is in Appendix I.

What follows is a brief description of each section of the Prologue. Note that no blank comment statements should occur until after the FUNCTIONS section.

A. CALUTNG SEQUENCE

The SUBROUTINE or FUNCTION statement should be the first line of the subprogram. Blanks should be used to enhance readability.

\section{B. PARAMETERS}

Declaration statements should be grouped by type, i.e., first INTEGER, then REAL, then DøUBIE PRECISION, or REAL*8, then REAL*16, then COMPLEX, CDMPLEX*32, then LOGICAL. Within each type grouping, variable names should be listed in the order they occur in the calling sequence. By parameters, we mean all of the variable names appearing in the calling sequence.

C. LOCAL VARTABLES

As with the preceding section, declaration statements are grouped by type, and in the same order. Within each type, variable names should be listed alphabetically.

Ald variables used in the program should be explicitly $\overline{\text { declared. }}$

D. FUNCTIONS

All functions called by the program should be explicitly declared. Declaration statements are grouped by type.

E. PURPOSE

Briefly describe the purpose of this subprogram. Give references when necessary. More detail can be given in later sections.

F. PARAMETER DESCRIPTION

This section contains 3 subsections. The first describes input parameters, the second describes output parameters, and the thind subsection describes parameters used for temporary storage by the subprogram. If the contents of any parameter variable can be changed by the subprogram, 
it should be considered an output parameter. See the examples in Appendix I for the format, keywords, punctuation and indentation used in this section.

\section{G. APPLICATION AND USAGE RESTRICTIONS}

If any other programs in this package can call this subprogram, or are called by it, they should be desscribed here. If this subprogram is part of a group of programs which are called in some specified order, this should also be included. Give references except when a reference is implicit, as with another member of the same package.

Also included in this section are any warnings about special cases or possible errors which can occur if there are errors in the subprogram call. Warnings about misuse of tolerance parameters belong here. The entry in PARAMETER DESCRIPTION should refer the reader to this section where applicable.

H. ALGORITHM NOTES

Anything special about the algorithm used or its implementation should be listed here. Any special conventions regarding statement labeling or conmenting should be mentioned. If there is anything special about error handling which has not yet been mentioned, it should be described here.

\section{REFERENCES}

References from elsewhere in the documentation, as well as any other references pertaining to the subprogram, should be listed.

\section{J. HISTORY}

The author of this subprogram, as well as the date and place of origin should be listed. If the subprogram is a translation of a program in another language or is based on another program, a reference should be given. If the program has been modified since it was written, the date and person making the modification should be noted. If this subprogram has been released as part of a subroutine library, the current release date of the library should be given.

K. GENERAL

If this subprogram was developed under research supported by a grant requiring acknowledgment, the required information should occur here. The person to contact concerning comments and problems with the subprogram should have his address in this section. 
L. DATA and EQUIVALANCE Statements

Following the second occurrence of delimiting comment statements (a blank comment statement, a comment statement with colons in columns 7 through 72 , and a second blank corment statement) is where all DATA and EQUTVAIENCE statements should occur. If a DATA statement contains an instaliation-dependent constant, conment statements explaining its value and mentioning the installation's designation, should precede the DATA statement. Those comment statements should conform to the standards of program-flow comments.

All DATA statements should precede any EQUIVALENCE staements.

M. BODY OF PROGRAM

This heading denotes the end of the Prologue and the beginning of the program body. 


\section{References}

[1] Dahl, O.H, Dijkstra, E.W., Hoare, C.A.R., Structured Progranming, Academic Press, (1972).

[2] Kernighan, B.W., Plauger, P.J., "Programing Style: Examples and CounterExamples," ACM Computing Surveys, Vol 6, No. 4, pp. 303-319, December, (1974).

[3] Kernighan, B.W., Plauger, P.J., "The Elements of Progranming Style," Bell Telephone Laboratories (1974). 
Appendix

This appendix contains listings of two subroutines that are samples of candidates for inclusion in ROSEPACK. The reader is reminded that we are relying on Fortran compiler optimization of sub-expressions within loops. 


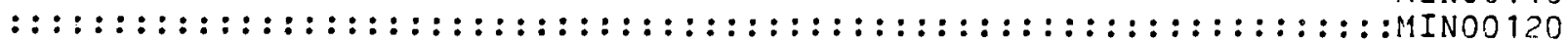

*****PURPOSE:

$M I N O O 130$

THIS SUBROUTINE DETERMINES A CANDIDATE SOLUTION TO THE LINEAR

MINO0140

SYSTEII $A X=B$, AFTER THE SINGULAR VALUE DECOIPOSITION A=USV OF $A$

HINOO 150

:IN INO0160

MINO0 170

IIINOO 180

REAL M BY N RECTANGULAR MATRIX, FORMING U 3 RATHER THAN U, HAS ALREADY BEEN PERFORMED. THIS CANDIDATE SOLUTION IS BASED ON THE RANK TOLERANCE PARAMETER, RKTOL, OR THE DEFAULT, 2.ODO**(-26), WHICH IS THE SQUARE ROOT OF THE MACHINE PRECISION 2. ODO** $(-52)$.

IIINOD 190

MINOO200

MINOO2 10

MINOO220

$M I N O 0230$

*****PARA:IETER DESCRIPIION :

ON INPUT:

11 INO0240

MIN00250

iiinOD260

NM MUST BE SET TO THE ROW DIMENSION OE THE TWO DIIENSIONAL ARRAY PARAMETERS AS DECLARED IN THE CALLING PROGRA:1

1IINO0270 DIMENSION STATEMENT;

!I IN 00280

HINOD290

1 IN 00300

11 IN 00310

iN IS THE NUMBER OF ROWS OF B, AND THE ORDER OE $V$;

"11ij0320

$V$ CONTAINS THE SQUARE MATRIX $V$ (ORTHOGANAL) OF THE SINGULAF VALUE DECOIPOSIMION;

111100330

IIINO0340

:1IIN00350

11 IIIOก 360

W CONTAINS THE N (NON-NEGATIVE) SINGULAR VALUES OF A (THE DIAGONAL ELEMENTS OF S). THEY ARE UNORDERED;

11 IN00370

11 INDO 380

11 INOO390

IP IS THE NUMBER OF COLULNS OF B;

B CONTAINS THE RECTANGIJLAR MATRIX U 3 ;

RKTOL IS THE RANK TOLERANCE WHICH WILL BE USED. IF RKTOL IS NOT POSITIVE, THEN THE DEFAULT WILL BE USED.

11 INDOHDO

:1 I I $1900+10$

iTnOD+20

11 INOOH 30

11 INOOH40

IIINOO 450

IIINDO460

iIIIIOO470

AINOD 480

ON OUTPUT:

$V$ RENAINS UNCHANGED;

$\checkmark$ CONTAINS THE PSEUDOINVERSE OE THE DIAGONAL MATRTX S. ANY SINGULAR VALUES THAT ARE LESS THAN RKTOL T'IMES THE LARGEST SINGULAR VALUE ARE SET' TO ZERO IN THE PSEUDCINVERSE;

B HAS BEEN OVERWRITTEN BY THE SOLUTION $X$;

IERR IS SET TO

ZERO FOR NORHAL RETURN,

-1 IF THE MAXIMUM SINGULAR VALUE IS ZERO (INDICATING A ZERO A-MATRIX IN THE SINGULAR VALUE DECOHPOSITION).

11 IN 00490

MINDO500

MINOO510

14 INO0520

MINO0 30

MIND0540

MNO0550

MIN00560

1INN00570

MIND0580

IIIN00590

II IN00600

11INN00610

IIIND0620

11INO0630

11 INO0640

HI IU00650 
**** *APPLICATION AND USAGE RESTRICTIONS:

IT IS RECOMMENDED THAT THE SUBROUTINE MINFIT (1) PERFORM THE

MIN00670

MIN00680 SINGULAR VALUE DECOMPOSITION.

THE IERR PARAMETER SHOULD BE CHECKED BEFORE CALLING MINSOL.

MIN00690

MIN00700

HIN007ה0

SETTING THE RANK TOLERANCE SHOULD ONLY BE DONE IF THE USER KNOWS THE SINGULAR VALUES OF THE A-MATRIX WITH RESPECT TO THE CERTAINTY MINOOT50 OF THE DATA.

MINOO760

*****ALGORITHM NOTES:

NONE

MIN00770

MIN00780

MIN00790

*****REFERENCES:

(i) ARGONNE NATIONAL LAB., FORTRAN SUBROUTINE MINFIT, ANLF233S.

(2) BECKER, R., KADEN, N., AND KLEMA, V., THE SINGULAR VALUE ANALYSIS IN MATRIX COMPUTATION" , NBER WORKING PAPER NO. 46 , (JULY 1974)

(3) GOLUB,G.H., AND REINSCH,C., 'SINGULAR VALUE DECOMPOSITION AND LEAST SQUARES SOLUTIONS", IN J.H. WILKINSON AND C. REINSCH (EDS.) HANDBOOK FOR AUTOHATIC COMPUTATION, VOLUME II:LINEAR ALGEBRA, SPRINGER VERLAG, 134-151 (1971); PREPUBLISHED IN

MIN00800

MIN 00810

MIN00820

MINO08 30

MIN 00840

11IN00850

MIN00860

MIN00870

UIN 00880 NUHER. MATH. 14, 403-420 (7970).

MIN00890

MINDO900

MINO0910

IIIN00920

*****HISTORY:

MINSOL IS BASED ON CODE WRITTEN BY FRED CIARAMAGLIA (NBER/COMPUTERMINOO930 RESEARCH CENTER; MAY 4,1973$)$.

11INDO940

MINOO950

ADAPTED BY NEIL KADEN (NBER/COMPUTER RESEARCH CENTEF) JUHE 9, 1975.11LHOO96D

DARE LAST HODIEIED: JUNE 11, 1975.

IIIO0970

*****GEVERAL:

QUESTIONS AND CO:11ENTS SHOULD BE DIRECTED TO: SUPPORT STAFF MANAGER

COMPUTER RESEARCH CENTER EOR ECONOMICS AND HANAGEMENT SCIENCE

NATIONAL BUREAU OF ECONOIIC RESEARCH

575 TECHNOLOGY SQUARE

CAMBRIDGE, HASSACHUSETTS 02139.

DEVELOPMENT OF THIS PROGRAM SUPPORTED IN PART BY

NATIONAL SCIENCE FOUNDATION GRANT GJ-1154X3 AND

NATIONAL SCIENCE FOUNDATION GRANT DCR75-08802

TO NATIONAL BUREAU OF ECONOMIC RESEARCH, INC,

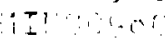

151000990

:IIIS 1000

MINO 1010

HINO 1020

MINO 1030

MINO 1040

MINO 1050

IIIND 1060

MINO 1070

MINO1080

iIIN01090

1IINO1100

MINO1110

MINO1120

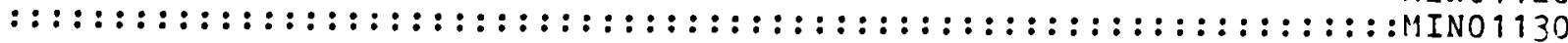

11 IN01140

$::::::::::$ RKTOL 1 , FOR THESE APPLICATIONS, IS A MACHINE DEPENDENT MINO1150 PARAMETER BASED ON THE SQUARE ROOT OF THE RELATIVE PRECISION OF FLOATING POINT ARITHMATIC.

MACHEP $=16.0 D 0^{*}(-13)$ EOR DOUBLE PRECISION ARITHMETIC

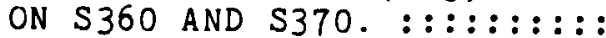

DATA RKTOL $1 / 23 A 40000000000000 \%$

MIN01160

MIN01170

MIN01180

IIINO1190

IIIN01200

MIN012.10

*****BODY OF PROGRAM:

$I E R R=0$

IF (RKTOL .LE. O.ODO) RKTOL = RKTOL 1

MIN01220

IIIN01230

HIN01240

$::::::::::$ FIND MAXIMUM ELEMENT OF $W::::::::::$

$Z=0.0 D 0$

MINO 1250

MINO1260

DO $750 \mathrm{~J}=1, \mathrm{~N}$

$X=W(J)$

IF (X.LE. Z ) GO TO 750

$Z=X$

MINO1270

MIN01280

VIN 0.1290

IIIN01300

750 CONTINUE

MIN01310

MINO1320

UINO1330 


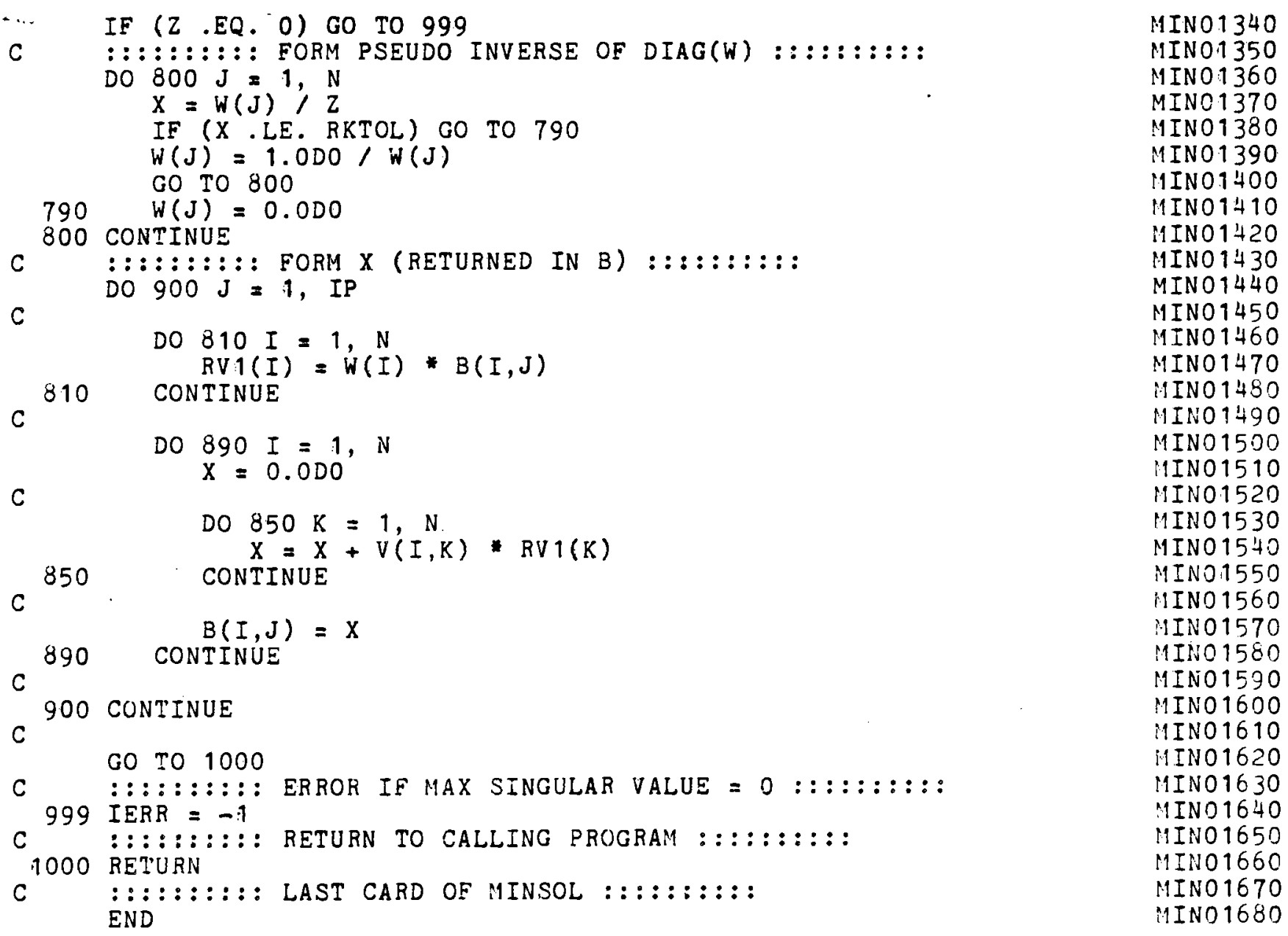

MINO1600

MINO 1610

MIN01620

MIN01630

IIN01640

MIN01650

MIN01660

MINO 1670

MINO1680 
***FUNCTIONS:

LUD00040

LUD00050

LUD00060

LUD00070

LUD00080

INTEGER MINO

LUD00090

REAL*8 DABS

LUD00100

LUD00110

THIS SUBROUTINE DOES AN LU DECOMPOSITION ON THE REAL M BY $N$ RECTANGULAR MATRIX A, WITH MODIFIED COMPLETE PIVOTING, AND RETURNS BOTH THE STRICT LOWER TRIANGLE OF L AND THE FULL UPPER TRIANGLE OF U.

\section{*****PARAMETER DESCRIPTION:}

ON INPUT:

NM IIUST BE SET TO THE ROW DIIIENSION OF THE TWO-DIIIEWSIONAL ARRAY PARALIETERS AS DECIAAED IN THE CALLIHG PROGRAI DIMENSION STATEIIENT;

M MUST BE SET TO THE NUMBER OE ROWS IN THE MATRIX;

W MUST BE SE: TO THE WUMBER OF COLUMNS IN THE !AATRIX;

A CONTAINS THE MATRIX TO BE FACTORED BY THE LUMDECOMPOSITION WITH COMPLETE PIVOTING;

IHTTC IS SET SUCH IHAT IE IHTTC(J) IS LESS THAN ZERO THEN THE J-TH COLUHN OF THE INPUT MATRIX CANIOT BE PIVOIED INTO THE FIRST $N$ COLUMNS OF ITS LU-DECOPIPOSITION. ALL ELEMENTS OF THIS VECTOR SHOULD BE SET TO ZERO TO INSURE NOHIIAL PIVOTING;

LUDOO120

LUD00140

LUDO0 150

LUDO0160

LUDO0 170

LUD00180

LUDDO 190

LUDO0200

LUD00210

LUD00220

LUDO0230

LUDOC?40

LUDO0250

LUDOO250

LUD002?0

LUDO0280

LUDD0290

LUDOO 300

LUDOO310

LUDO0 320

LUDO0 330

LUDO0340

LUD00350

LUDD0360

LUD00370

LUDD0 380

LUDOD390

ON OUTPUI:

LUDOO400

LUDOO+ 10

A CONTAINS THE LMATRIX AND THE UMATRIX AS FOLLOWS:

LUDDO 420 A( ROW $(I)$, COL $(J)$ ) FOR I LESS THAN OR EQUAL TO J CONTAIINS THE (I,J) ELEMENTS OE THE UPPER TRIANGULAR U-MATRIX; A( ROW $(I)$, COL $(J)$ ) FOH I GREATER THAN J CONTAINS THE

LUDOD 430

LUDDO $4+40$

LUDOO 450 SUB-DIAGONAL ( $I, J)$ ELEMENTS OF THE L-MATRIX. FHE DIAGONAL LUDOO 460 OF I'HE L-MATRIX CONTAINS ALL ONES;

LUDOO +70

LUDOO 450

LUDOO 490

IROW REELECTS THE ROW PIVOTING PERFORIIED. IF IROW(J) IS EQUAL TO K THEN THE J-TH ROW WAS PIVOTED INTO THE K-TH ROW-POSITION. SEE ALSO THE OUTPUT DESCRIPIION OF A;

LUDOD500

LUDO0510

LUD00520

ICOL REFLECTS THE COLUMN PIVOTING PEREORMED. SEE ALSO THE OUTPUT DESCRIPTION OF IROW;

LUDOD530

LUDO0540

LUD00550

LUDOO560

IERR IS SET TO ZERO FOR NORMAL EXITS. IT IS SET TO $K$, WHERE $K$ IS AN INTEGER DENOTING THE CURRENT ITERATION. IF NO ACCEPTABLE PIVOTS COULD BE FOUND (AN ACCEPTABLE PIVOT IS A NCN-ZERO ONE WITH THE LUD00570 CORRESPONDING ELENENT OF IHTTC NON-NEGATIVE).

LUDO0580 IF AN ERROR EXIT IS TAKEN, THE DECOMPOSITION HAS ONLY BEEN PERFORMED FOR K-1 ITERATIONS.

LUDO0590

LUD00600

LUD00610

LUDO0620

LUD00630 


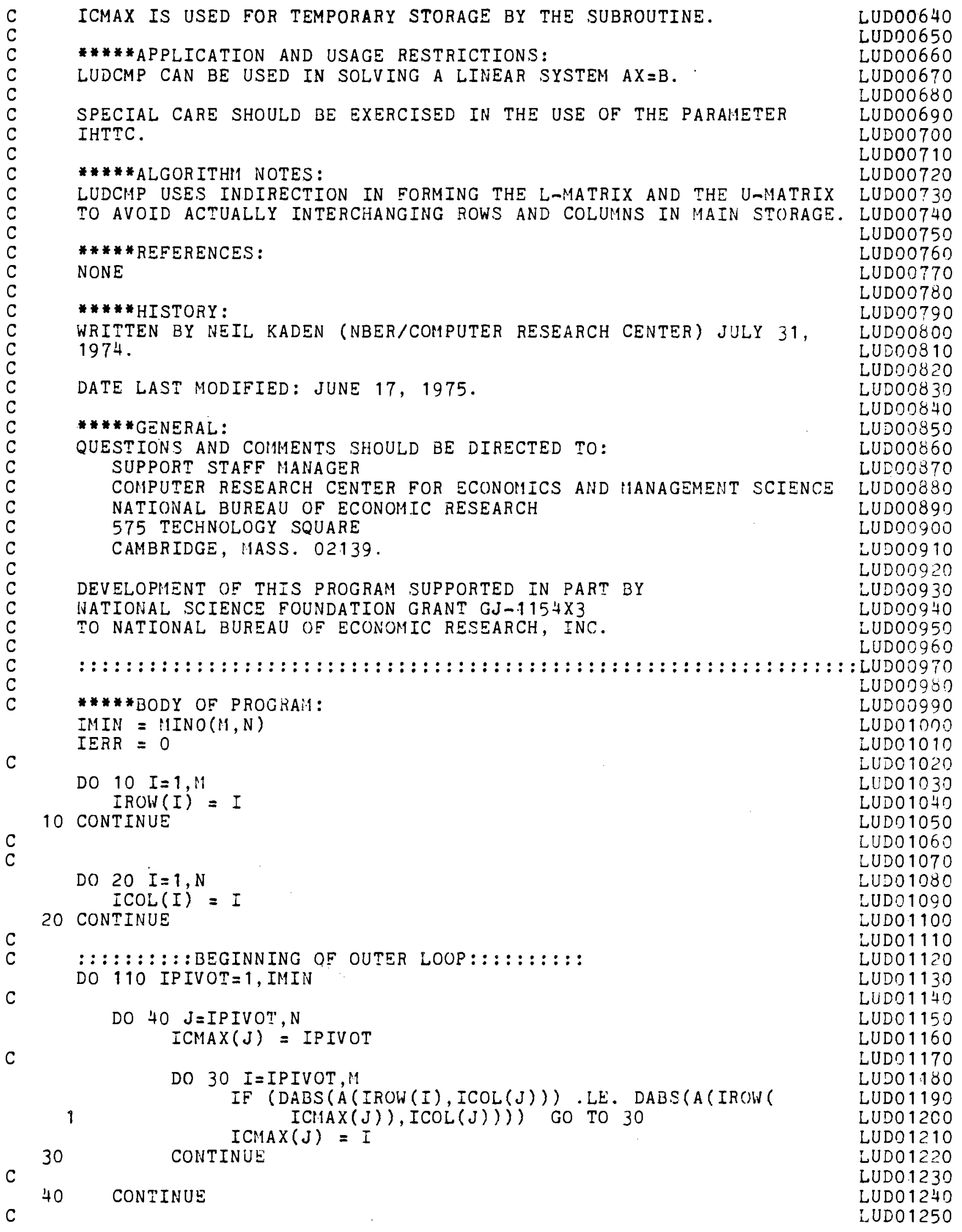




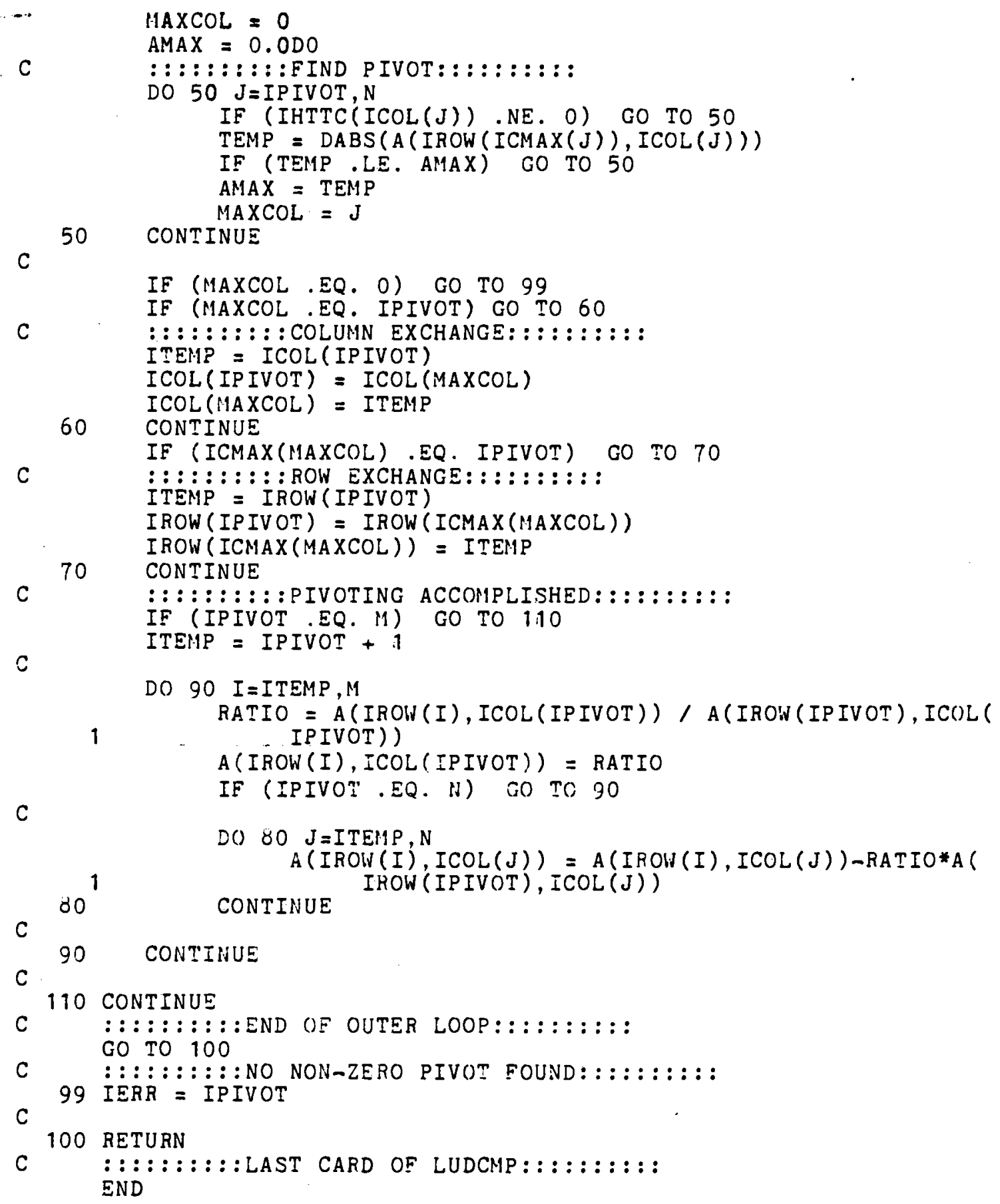

C IF (IPIVOI . EQ. H) GO TC 90

C

90 CONTINUE

C

LUDO 1390

LUDO1400

LUDO1410

LUD01420

LUDO 1430

LUDO 1440

LUDO 1450

LUDO1460

LUDO1470

LUDO 1480

LUDO1490

LUD01500

LUDO 1510

LUD 01520

LUDO 1530

LUDO 1540

LUD01550

¿UD0 1560

LUD01570

LUDO 1580

LUD01590

LUD01600

LUD01610

LUD01620

LUD01630

LUD0 1640

LUD0 1650

LUDD 1660

LUDO1670

LUD01680

LUD01690

LUDO 1700

LUDO 1710

LUD0 1720

LUDO 1730

LUD01740

LUD01750 